\title{
THE EFFECT OF CHANGE IN BODY POSITION ON LUNG VOLUME AND INTRAPULMONARY GAS MIXING IN NORMAL SUBJECTS ${ }^{1}$
}

\author{
By E. BLAIR 2 AND J. B. HICKAM \\ (From the Department of Medicine, Duke University School of Medicine, Durham, N. C.)
}

(Submitted for publication September 27, 1954 ; accepted November 3, 1954)

In many normal people a sizable part of the lung is ventilated at a much slower rate than the remainder. Means have been devised for measuring the volume and ventilation rate of these "slow spaces" (1-4). It is also established that a change in body position from sitting to recumbent will alter the size of the various subdivisions of the lung volume $(5,6)$. In the course of some observations on intrapulmonary gas mixing, it was found that changes in body position caused significant changes in size and ventilation rate of the "slow spaces." It is the purpose of this paper to present the results of a study of the effects of various body positions on lung volumes and on the size and ventilation rate of the poorly ventilated regions of the lung.

\section{METHODS}

The functional residual capacity (FRC) and the vollume $\left(V_{s}\right)$ and minute ventilation rate $\left(\dot{V}_{s}\right)$ of the most poorly ventilated lung space were measured by an opencircuit helium method (4). The subject breathes a mixture of 50 per cent helium and 50 per cent oxygen for fifteen minutes to achieve a nearly uniform concentration of helium throughout the lungs. At the end of a normal expiration he is switched to tank oxygen, and the expired gas is thereafter collected for subsequent measurement of volume and helium concentration. In addition, the helium concentration of the expired gas is continuously followed by a sensitive katharometer between helium levels of 3.30 and 0.05 per cent. When the helium concentration reaches 0.05 per cent, the analysis is abandoned. The FRC is calculated, as in other opencircuit methods, from the total quantity of helium excreted during the washout period and the mean intrapulmonary concentration of helium at the start of the washout. For measuring the slow space, a plot of helium

1 This work was supported, in part, by a research grant H-1370(C) from the National Institutes of Health, Public Health Service, and, in part, by the Life Insurance Medical Research Fund.

2 U. S. Public Health Service Post-doctorate Research Fellow. Present address: University of Colorado Medical Center, Denver. concentration in the expired air against time is made on semi-logarithmic paper. The terminal part of this curve, which is produced by helium excretion from the slow space, approximates a straight line. The emergence of a straight line indicates that those parts of the lung which are still excreting helium are being ventilated enough alike so that they constitute, in effect, a single homogeneously ventilated lung space. The straight line toward which the curve tends during the last few minutes of the washout is drawn in "by eye." From the slope of this line, the point at which it intersects the ordinate at zero time, and from the minute ventilation rate of the subject, it is possible to estimate the ventilation rate and volume of the slow space.

In the present study the expressions $k_{\mathbf{a}}$ and $f$ are used to characterize the slow space. $k_{z}$ is the "turnover rate" of the slow space, or ratio of its minute ventilation to its volume $\left(\dot{V}_{a} / V_{s}\right)$. For the lung as a whole, $k$ is usually between 2 and 3 if the subject is in a basal or nearbasal state. For the whole lung, $\mathrm{k}$ represents the ratio between total minute ventilation and the functional residual capacity. The present subjects were not basal and the ratio between minute ventilation and FRC was about 4 , for seated subjects. The relative size of the slow space is expressed as the ratio, $f$, between the volume of the slow space and the functional residual capacity.

The present method is not well suited to the measurement of rapidly ventilated lung spaces because of the lag in response of the katharometer to change in helium concentration. A 95 per cent response occurs in 20 seconds. In addition, it requires 5 to 8 seconds for expired gas to pass from the subject to the sampling point. Although an allowance can be made for these delays, inexactness in the allowance may introduce serious errors into the estimates of ventilation rate and volume of lung spaces which have a very rapid turnover rate. The analytical system can measure accurately $k$ values of at least 3.0, as demonstrated by results obtained with simulated lungs having a known volume and ventilation rate. Consequently, the ratio of ventilation rate to volume can be determined even for a space which is this rapidly washed. However, the actual values of ventilation rate and volume also depend on the point where the extrapolated straight line, whose slope is measured as $k$, intercepts the ordinate. The larger the value of $\mathrm{k}$, and the steeper the resultant slope, the greater will be the error introduced by inexactness in timing. The error in ventilation rate and volume is proportional to the error made in determining the concentration value, $C_{0}$, where the line in- 
tercepts the ordinate. This error can be calculated for a given time error from the equation for the line: $\ln \frac{C}{C_{0}}=-k t$. If it is assumed that instrumental lag is 15 seconds greater than the allowance, then volume and ventilation rate of the slow space will be 5 per cent too great for a $\mathbf{k}$ of $0.2 ; 13$ per cent for a $k$ of $0.5 ; 28$ per cent for $a k$ of 1.0 ; and 65 per cent for $a k$ of 2.0. The absolute magnitude of the error in ventilation rate and volume depends upon the value of $C_{0}$. The ventilation rate of the slow space, $\dot{V}_{\mathbf{s}}$, is estimated as: $\dot{V}_{\mathbf{s}}=\dot{\mathrm{V}}_{\mathbf{t}} \frac{\mathrm{C}_{\mathbf{0}}}{\mathbf{0 . 5 0}}$, where $\dot{V}_{t}$ is the total ventilation rate and 0.50 is the concentration of helium in the space at the start of the washout (4). If, for example, $\dot{V}_{t}$ is 10 liters per minute, $C_{0}$ is .075 (or 7.5 per cent), $k$ is 1.0 , and the error is 15 seconds, then $V$. will be calculated as $1920 \mathrm{ml}$. per minute instead of the correct value of $1500 \mathrm{ml}$. per minute. On the basis of these considerations it has been decided not to attempt to calculate volume and ventilation rate for spaces having a $k$ greater than 1.0 or a $C_{0}$ greater than .075 . This rule is followed in the present study.

The vital capacity and its subdivisions were measured with a spirometer in the conventional way.

Measurements of the lung volumes and of the most slowly ventilated space were made with the subjects seated, standing, recumbent (supine), in the right and left lateral positions, and in a $30^{\circ}$ head-down Trendelenburg position. The subjects were 12 normal males with an age range of 23 to 39 years. In all 12 subjects measurements were made of the FRC and, in 11 instances, of intrapulmonary mixing in the seated, standing, and recumbent positions at a single, uninterrupted study period. These subjects are designated as "Group A." In 9 subjects measurements were made in the recumbent, lateral, and Trendelenburg positions during a single study period, and these subjects are designated as "Group B." In some instances all measurements were made at a single session. After each individual measurement a rest period of several minutes was allowed, during which the subjects moved freely about and assumed various body positions at will.

\section{RESULTS}

\section{Effect of body position on lung volumes}

The data on lung volumes in different body positions are summarized in Tables IA and IB and are presented graphically in Figure 1. For cal-

TABLE IA

Postural changes in-lung volumes (liters)

Normal subjects, group $A$

\begin{tabular}{|c|c|c|c|c|c|c|c|}
\hline & \multirow{2}{*}{$\begin{array}{l}\text { Number of } \\
\text { subjects }\end{array}$} & \multicolumn{2}{|c|}{ Sitting } & \multicolumn{2}{|c|}{ Standing } & \multicolumn{2}{|c|}{ Recumbent } \\
\hline & & Mean & S.D. & Mean & S.D. & Mean & S.D. \\
\hline $\begin{array}{l}\text { Vital capacity } \\
\text { Inspiratory capacity } \\
\text { Expiratory reserve } \\
\text { Functional residual capacity } \\
\text { Residual capacity } \\
\text { Total capacity } \\
\text { RC/TC } \times 100\end{array}$ & $\begin{array}{r}9 \\
9 \\
9 \\
12 \\
9 \\
9 \\
9\end{array}$ & $\begin{array}{r}4.96 \\
3.18 \\
1.80 \\
3.30 \\
1.40 \\
6.36 \\
22\end{array}$ & $\begin{array}{r}.55 \\
.50 \\
.32 \\
.45 \\
.52 \\
.59 \\
7\end{array}$ & $\begin{array}{l}4.96 \\
3.10 \\
1.85 \\
3.79 * \\
1.81 \dagger \\
6.77 \dagger \\
27 \ddagger\end{array}$ & $\begin{array}{r}.47 \\
.44 \\
.36 \\
.40 \\
.40 \\
.42 \\
5\end{array}$ & $\begin{array}{l}4.64^{*} \\
3.70^{*} \\
0.94^{*} \\
2.62^{*} \\
1.58 \\
6.22 \\
25\end{array}$ & $\begin{array}{r}.43 \\
.56 \\
.21 \\
.60 \\
.60 \\
.65 \\
8\end{array}$ \\
\hline
\end{tabular}

* Significantly different from the value obtained in the seated position $(p<.01)$.

+ Significantly different from the value obtained in the seated position $(\mathrm{p}<.02)$.

$\ddagger$ Significantly different from the value obtained in the seated position $(p<.05)$.

TABLE IB

Postural changes in lung volumes (liters)

Normal subjects, group $B$

\begin{tabular}{|c|c|c|c|c|c|c|c|c|}
\hline & \multicolumn{2}{|c|}{$\begin{array}{l}\text { Recumbent } \\
\text { (9 subjects) }\end{array}$} & \multicolumn{2}{|c|}{$\begin{array}{c}\text { Right lateral } \\
\text { (8 subjects) }\end{array}$} & \multicolumn{2}{|c|}{$\begin{array}{l}\text { Left lateral } \\
\text { (8 subjects) }\end{array}$} & \multicolumn{2}{|c|}{$\begin{array}{c}\text { Trendelenburg } \\
\text { (9 subjects) }\end{array}$} \\
\hline & Mean & S.D. & Mean & S.D. & Mean & S.D. & Mean & S.D. \\
\hline $\begin{array}{l}\text { Vital capacity } \\
\text { Inspiratory capacity } \\
\text { Expiratory reserve } \\
\text { Functional residual capacity } \\
\text { Residual capacity } \\
\text { Total capacity } \\
\text { RC/TC X } 100\end{array}$ & $\begin{array}{r}4.64 \\
3.70 \\
0.94 \\
2.47 \\
1.54 \\
6.18 \\
24\end{array}$ & $\begin{array}{l}.43 \\
.56 \\
.21 \\
.55 \\
.48 \\
.75 \\
5\end{array}$ & $\begin{array}{l}4.43 \\
3.13^{*} \\
1.31^{*} \\
2.89 \dagger \\
1.58 \\
6.01 \\
26\end{array}$ & $\begin{array}{l}.33 \\
.43 \\
.47 \\
.46 \\
.46 \\
.67 \\
5\end{array}$ & $\begin{array}{l}4.64 \\
3.23^{*} \\
1.41^{*} \\
2.91 \dagger \\
1.50 \\
6.13 \\
25\end{array}$ & $\begin{array}{r}.59 \\
.46 \\
.27 \\
.35 \\
.32 \\
.65 \\
5\end{array}$ & $\begin{array}{l}4.32^{*} \\
3.62 \\
0.70^{*} \\
2.10 \dagger \\
1.41 \\
5.72^{*} \\
24\end{array}$ & $\begin{array}{r}.53 \\
.58 \\
.12 \\
.57 \\
.47 \\
.74 \\
4\end{array}$ \\
\hline
\end{tabular}

* Significantly different from the value obtained in the recumbent position $(p<.01)$.

+ Significantly different from the value obtained in the recumbent position $(p<.02)$. 


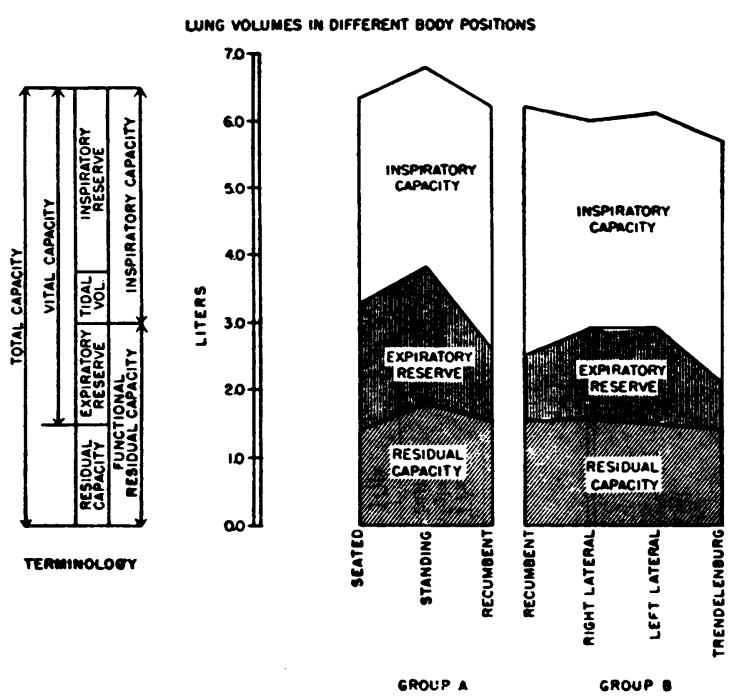

Fig. 1. The Effect of Body Position on the Conventional Subdivisions of the Lung Volume in Normal Subjects

There are 12 subjects in Group A and 9 in Group B.

culating the statistical significance of changes in lung volumes, the sitting position is taken as the standard of reference for Group $A$ and the recumbent (supine) position as the standard for Group B.

The residual capacity proved to be quite stable. In the standing position it was significantly larger than in the sitting, but otherwise it was not significantly changed. Hurtado and Fray (5) and Whitfield, Waterhouse, and Arnott (6) reported that the residual capacity decreased on passing from the sitting to the supine position but this did not occur in the present study. The functional residual capacity (FRC), on the other hand, varied considerably with body position. For the most part, changes in FRC were based on corresponding changes in the expiratory reserve. In broad terms, the FRC, or lung volume at the relaxation point, was greatest in the standing position and became progressively less on passing to sitting, recumbent, and Trendelenburg positions. The difference in FRC between standing and Trendelenburg positions was approximately 1700 $\mathrm{ml}$. Changing from the supine to a lateral position caused a significant increase in FRC, averaging about $400 \mathrm{ml}$. The total capacity was largest in the standing and least in the Trendelenburg position. The average difference was approxi- mately $1000 \mathrm{ml}$. Except for the residual capacity, the changes in lung volumes between seated and recumbent positions are similar to those reported by others. For the other body positions no data appear to be available for comparison.

\section{The effect of body position on intrapulmonary gas mixing}

Changes in intrapulmonary gas mixing are expressed as changes in the volume $\left(V_{s}\right)$ and ventilation rate $\left(\dot{V}_{\mathrm{B}}\right)$ of the most slowly ventilated lung space. These values and the relative volume, $f$, and relative ventilation rate, $k_{\mathrm{B}}$, of the slow space are presented in Tables IIA and IIB. No difference is apparent between the seated and standing positions (Table IIA). In each position the slowest space in four of the 11 subjects was too rapidly ventilated to be measured. Assuming the recumbent position produced a definite change in intrapulmonary mixing. All but one subject demonstrated a measurable slow space in the recumbent position. The relative ventilation rate, $\mathbf{k}_{\mathrm{s}}$, of the slow space for the group as a whole was approximately half as fast as in the seated or standing positions. This decrease is statistically significant. In addition, the slow space decreased in size or, in two cases, remained virtually unchanged on passing from standing or sitting to the recumbent position. On changing from the recumbent to the Trendelenburg position, $k_{s}$ again became significantly smaller, but the volume of the slow space remained about the same. In association with the decrease in relative ventilation rate of the slow space on lying down, there was a small but statistically significant decrease in total ventilation rate. However, the decrease in functional residual capacity (Table IA) was proportionately greater than the drop in total ventilation rate, so that the relative ventilation rate of the lung as a whole was increased on lying down. On changing from recumbent to lateral positions, there was no significant change in volume or ventilation rate of the slow space.

In summary, the functional residual capacity became smaller when a sitting or standing subject lay down, and it became smaller still in the Trendelenburg position. These changes depended primarily upon changes in the expiratory reserve volume, since the residual air changed very little. 

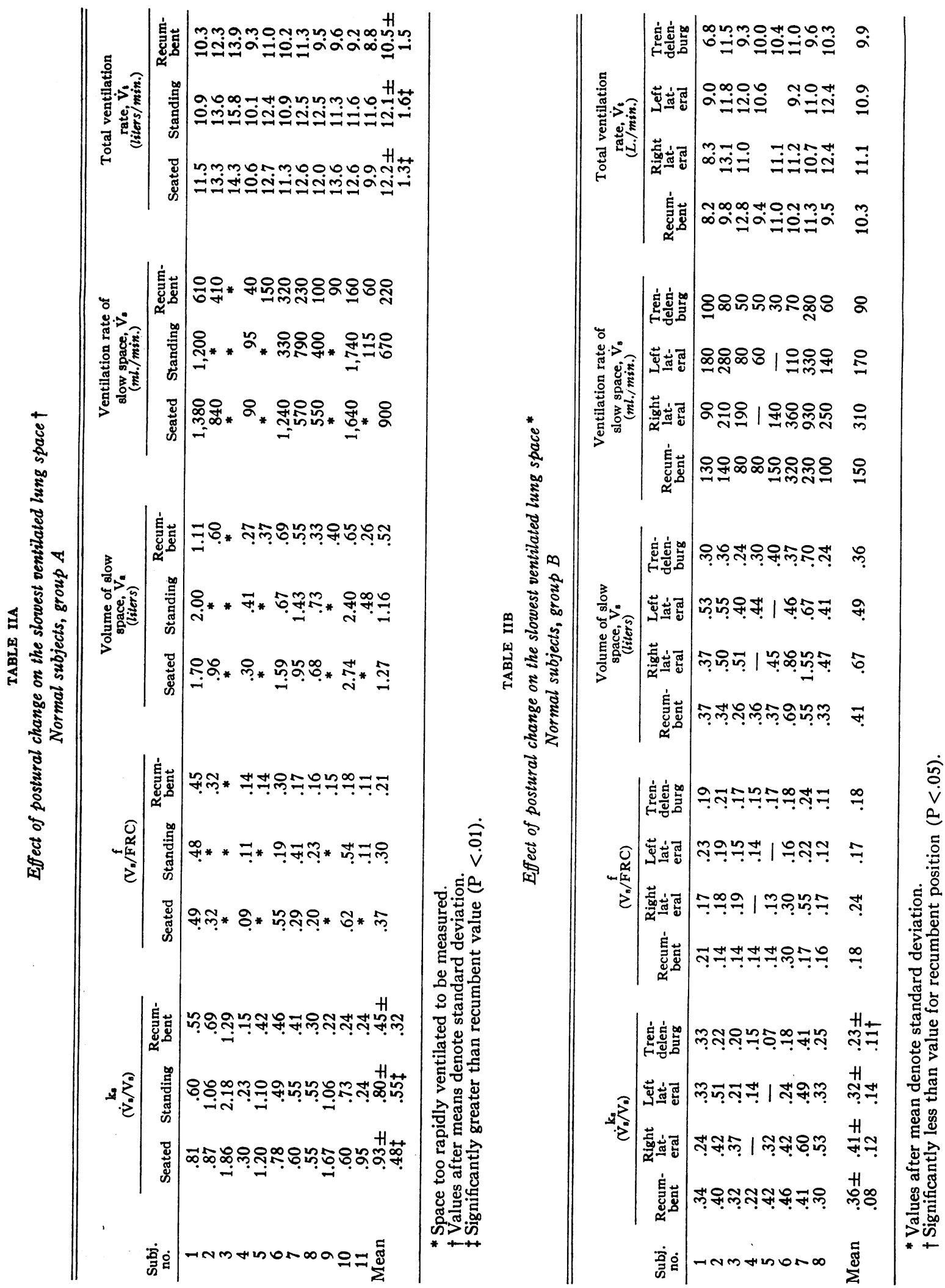

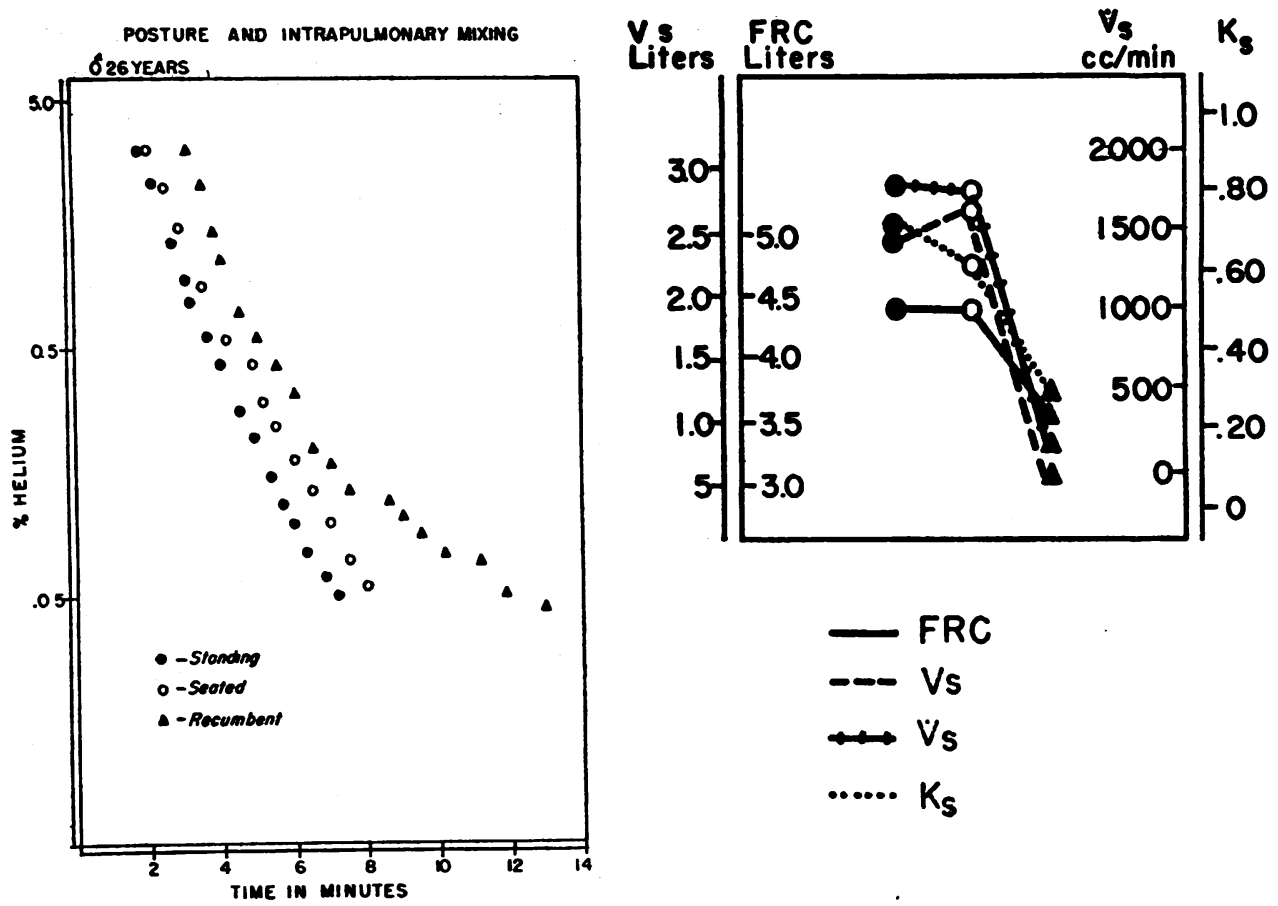

Fig. 2. The Effect of Postural Change on Functional Residual Capactiy and Intrapulumonary Gas Mixing in a Normal Person

The diagram on the left demonstrates the changes in helium washout curve of a normal subject resulting from changes in body position. On the right there is a diagrammatic presentation of the changes in functional residual capacity (FRC), volume of the most slowly ventilated lung space $\left(V_{8}\right)$, minute ventilation rate of the space $\left(\dot{V}_{8}\right)$, and ratio of $\dot{V}_{\mathrm{s}}$ to $V_{8}\left(k_{8}\right)$, with change in body position. Values in the standing position are represented by solid circles; seated by open circles; and recumbent, by triangles.

On lying down, the most slowly ventilated space became smaller and more poorly ventilated, and in the Trendelenburg position it became still more poorly ventilated. In the Trendelenburg position, on the average, about a fifth of the resting lung volume was being ventilated at about one-twen- tieth of the mean ventilation rate for the lungs as a whole. Within the limitations of the method, lying on the side did not make intrapulmonary mixing less even than it was in the recumbent position.

Figure 2 illustrates some of the changes pro-

TABLE III

Postural changes in lung volume and in the slowest ventilated space: Lung disease

\begin{tabular}{|c|c|c|c|c|c|c|}
\hline & \multicolumn{2}{|c|}{$\begin{array}{l}\text { W. J. ơ } 30 \text { years } \\
\text { Cystic disease }\end{array}$} & \multicolumn{2}{|c|}{$\begin{array}{l}\text { M. W. O o } 52 \text { years } \\
\text { Fibrosis, Emphysema }\end{array}$} & \multicolumn{2}{|c|}{$\begin{array}{l}\text { J. B. } \text { or }^{7} 60 \text { years } \\
\text { Empysema }\end{array}$} \\
\hline & Seated & Recumbent & Seated & Recumbent & Seated & Recumbent \\
\hline $\begin{array}{l}\text { Vital capacity } \\
\text { Inspiratory capacity } \\
\text { Expiratory reserve } \\
\text { Functional residual capacity } \\
\text { Residual capacity } \\
\text { Total capacity } \\
\text { RC/TC X } 100\end{array}$ & $\begin{array}{r}2.20 \\
1.10 \\
1.10 \\
2.33 \\
1.23 \\
3.43 \\
36\end{array}$ & $\begin{array}{r}1.92 \\
1.12 \\
.81 \\
2.31 \\
1.50 \\
3.42 \\
44\end{array}$ & $\begin{array}{r}2.12 \\
1.62 \\
.50 \\
4.35 \\
3.85 \\
6.32 \\
67\end{array}$ & $\begin{array}{r}2.47 \\
1.97 \\
.50 \\
4.29 \\
3.79 \\
6.26 \\
61\end{array}$ & $\begin{array}{r}2.28 \\
1.45 \\
.83 \\
7.23 \\
6.40 \\
8.68 \\
74\end{array}$ & $\begin{array}{r}2.18 \\
1.28 \\
.91 \\
6.78 \\
5.87 \\
8.05 \\
73\end{array}$ \\
\hline $\begin{array}{l}\mathbf{k} . \\
\mathbf{f} \\
\mathbf{V}_{0} \text { (liters) } \\
\dot{\mathrm{V}} . \text { (ml.mir.) }\end{array}$ & $\begin{array}{c}.39 \\
.49 \\
1.150 \\
450\end{array}$ & $\begin{array}{r}.41 \\
.20 \\
.47 \\
190\end{array}$ & $\begin{array}{r}.22 \\
.55 \\
2.40 \\
530\end{array}$ & $\begin{array}{r}.06 \\
.46 \\
1.99 \\
120\end{array}$ & $\begin{array}{r}.13 \\
.53 \\
3.80 \\
490\end{array}$ & $\begin{array}{r}.11 \\
.50 \\
3.36 \\
370\end{array}$ \\
\hline
\end{tabular}


duced in a normal subject by change in body position.

Table III summarizes the effect on lung volumes and slow space of changing from the seated to the recumbent position in three patients with lung disease. One patient had cystic disease and the other two had emphysema. There is relatively little change in expiratory reserve and functional residual capacity between the seated and lying positions. These subjects do not show the normal tendency of the resting lung volume to become smaller in recumbency. The two patients with emphysema have very large, poorly ventilated slow spaces. Change in body position produces no striking change in these spaces.

\section{DISCUSSION}

The present data show considerable inequality of ventilation in the lungs of normal subjects, particularly in the recumbent and Trendelenburg positions. In these positions, the most slowly ventilated space amounted, on the average, to about a fifth of the functional residual capacity. The ratio of minute ventilation to volume in the slow space was about one-third in recumbency and onequarter in the Trendelenburg position (Table IIB). If the normal resting pulmonary blood flow were evenly distributed through the functional residual volume, these low ventilation rates would result in ventilation-perfusion ratios in the slow space of about 1 to 7 in recumbency and 1 to 12 in the Trendelenburg position. Blood perfusing these regions would be poorly aerated and would furnish a large "venous admixture" to the arterial blood. From the data of Riley and Cournand $(7,8)$ it appears that the amount of venous admixture would considerably exceed normal limits. In fact, the arterial blood oxygen saturation at sea level should fall below 95 per cent. Since the arterial oxygen saturation is normally well maintained in recumbency, it is probable that perfusion, as well as ventilation, is reduced in the slowly ventilated space. Such a result would be favored by the development of a reduced oxygen tension in regions where the ventilation-perfusion ratio is very low $(9,10)$. It has been pointed out that a local increase in pulmonary vascular resistance resulting from local hypoxia can be beneficial in shunting blood away from portions of the lung where aeration is impaired by disease (11). The present finding that ventilation can be greatly reduced in some parts of the lung by change in body position suggests that a similar shunting mechanism may be used to maintain normal arterial oxygenation under physiological conditions in healthy subjects.

A study of the effect on intrapulmonary gas mixing of a voluntary change in end-expiratory lung volume in normal subjects in the sitting position has been reported recently by Bates, Fowler, Forster, and Van Lingen (12). The volume of the slowly ventilated space changed in proportion to the end-expiratory lung volume, but the slow space continued to get the same share of the effective ventilation at different lung volumes. Accordingly, the turnover rate of the slow space increased as its volume decreased. The opposite effect on turnover rate was found in the present study when the volume of the slow space was decreased by recumbency.

The location of those portions of the lung which comprise the slow space is not known. Uniform involvement of large portions of the lung, particularly a segment supplied by a single bronchus, would presumably encourage atelectasis during prolonged recumbency. The development of these large slow spaces in normal subjects during recumbency emphasizes the desirability of frequent change in body position and occasional periods of induced hyperventilation in the care of unconscious patients or those who are confined to a respirator.

Passing from the standing to the recumbent position causes a decrease in the resting capacity or relaxation volume of the lung amounting to about $1200 \mathrm{ml}$., and assuming the Trendelenburg position causes a further decrease of 400 to $500 \mathrm{ml}$. These changes apparently result from a progressive elevation of the diaphragm, presumably because of pressure from the abdominal viscera. It is also possible that the resting tone of the diaphragmatic muscle may be decreased in the recumbent position. This large change in lung volume, and the attendant change in position of the bronchi, may account for the paroxysms of coughing which often develop when patients with bronchitis and an active cough reflex assume the recumbent position. 


\section{SUM MARY}

1. Using an open-circuit helium method, measurements have been made in normal subjects of the effect of change in body position on the conventional subdivisions of the lung volume and on the size and ventilation rate of the most slowly ventilated portion of the lung. The subjects were studied in the standing, seated, supine, right and left lateral, and Trendelenburg positions.

2. The functional residual capacity became progressively smaller on passing from the standing to the seated position, from seated to recumbent, and from recumbent to Trendelenburg. These changes depended primarily upon changes in expiratory reserve volume, since the residual capacity changed very little.

3. Most of the subjects demonstrated in the standing and seated positions a slowly ventilated lung space which could be measured by the present technique. On recumbency, all subjects but one demonstrated such a space. In general, the "slow space" became smaller and more slowly ventilated when the subjects lay down, and its ventilation rate was still further reduced in the Trendelenburg position. The volume of the slow space was approximately a fifth of the functional residual capacity in recumbent and head-down subjects. The minute turn-over rate of these slow spaces was, in general, less than 0.5 .

\section{REFERENCES}

1. Robertson, J. S., Siri, W. E., and Jones, H. B., Lung ventilation patterns determined by analysis of nitrogen elimination rates; use of the mass spectrometer as a continuous gas analyzer. J. Clin. Invest., 1950, 29, 577.
2. Fowler, W. S., Cornish, E. R., Jr., and Kety, S. S., Lung function studies. VIII. Analysis of alveolar ventilation by pulmonary $\mathrm{N}_{2}$ clearance curves. J. Clin. Invest., 1952, 31, 40.

3. Briscoe, W. A., Further studies on the intrapulmonary mixing of helium in normal and emphysematous subjects. Clin. Sc., 1952, 11, 45.

4. Hickam, J. B., Blair, E., and Frayser, R., An opencircuit helium method for measuring functional residual capacity and defective intrapulmonary gas mixing. J. Clin. Invest., 1954, 33, 1277.

5. Hurtado, A., and Fray, W. W., Studies of total pulmonary capacity and its subdivisions. III. Changes with body posture. J. Clin. Invest., 1933, 12, 825.

6. Whitfield, A. G. W., Waterhouse, J. A. H., and Arnott, W. M., The total lung volume and its subdivisions. A study in physiological norms. I. Basic data. Brit. J. Social Med., 1950, 4, 1.

7. Riley, R. L., and Cournand, A., 'Ideal' alveolar air and the analysis of ventilation-perfusion relationships in the lungs. J. Applied Physiol., 1949, 1, 825.

8. Riley, R. L., and Cournand, A., Analysis of factors affecting partial pressures of oxygen and carbon dioxide in gas and blood of lungs: Theory. $J$. Applied Physiol., 1951, 4, 77.

9. Motley, H. L., Cournand, A., Werko, L., Himmelstein, A., and Dresdale, D., The influence of short periods of induced acute anoxia upon pulmonary artery pressures in man. Am. J. Physiol., 1947, $150,315$.

10. Atwell, R. J., Hickam, J. B., Pryor, W. W., and Page, E. B., Reduction of blood flow through the hypoxic lung. Am. J. Physiol., 1951, 166, 37.

11. Lilienthal, J. L., Jr., and Riley, R. L., Diseases of the respiratory system. Circulation through the lung and diffusion of gases. Ann. Rev. Med., 1954, $5,237$.

12. Bates, D. V., Fowler, W. S., Forster, R. E., and Van Lingen, B., Uniformity of alveolar ventilation at different lung volumes. J. Applied Physiol., 1954, 6, 598.

\section{SPECIAL NOTICE TO SUBSCRIBERS}

Post Offices will no longer forward the Journal when you move.

Please notify The Journal of Clinical Investigation, Business Office, 622 West 168th Street, New York 32, N. Y. at once when you have a change of address, and do not omit the zone number if there is one. 